\title{
ОТРАСЛЕВОЙ И СЕКТОРАЛЬНЫЙ АНАЛИЗ ГЛОБАЛЬНОГО КЛАСТЕРНОГО РАЗВИТИЯ
}

\section{(c) 2019 Карпичев Евгений Владимирович}

соискатель кафедры экономики и управления предприятиями и производственными комплексами Санкт-Петербургский государственный экономический университет 191023, Санкт-Петербург, ул. Садовая, д. 21

E-mail:kev@szfo.gov.ru

Автором предложен отраслевой и секторальный анализ глобального кластерного развития по статистическим наблюдениям «Глобального инновационного рейтинга» и данным OECD (2018), раскрытый через научно-исследовательские индикаторы 100 ведущих мировых промышленных кластеров. Выделены и раскрыты 5 ключевых экономических тенденций глобального кластерного развития, формулируемые как перспективы институционального развития национальных промышленных кластеров.

\section{Ключевые слова: кластеры, экономика промышленности.}

Кластеризация в современной академической теории определена как наиболее перспективная форма хозяйственной интеграции, поскольку сохраняет принципы конкуренции и отвечает инновационной парадигме экономического роста. Темпы развития территориальных агломераций промышленности в странах с «высоким доходом» (классификация Мирового Банка) отражают объективность кластера (рисунок 1), как «новой волны развития капитализма» (Тоффлер Э., 1999, [3]). В развитие традиционного понимания MAR-эффектов кластеризации, на современном этапе ученые-экономисты акцентируются и на «активизации инновационной активности».

Именно поэтому включение индексов научно-технического развития в мониторинговые показатели, анализ инновационных процессов и результатов промышленных агломераций становится важнейшей частью экономических исследований кластеров на современном этапе.

Динамика валовых экономических показателей российских кластеров (рисунок 2) объективно позитивная, несмотря на «начальный» этап развития большинства объединений (5-7 лет). Поступательный рост инвестиций в основные фонды и НИОКР свидетельствует об экономически эффективном развитии промышленности на кластерной платформе. Но сохраняется вопрос об оптимальности структуры, институциональной организации и принципах кооперации субъектов кластеров. Ответ на данный вопрос целесообразно построить на анали- зе актуальных тенденций глобального кластерного развития, имеющего значительно более долгий контекст (20-30 лет) становления организационных рыночных отношений субъектов промышленных объединений.

Исследование ключевых тенденций глобального кластерного развития автор построил на статистических данных «Глобального инновационного индекса» (далее - GII, 2018, [11]), мониторинговых данных OECD (2018, [7]) и кейс-анализе 100 ведущих мировых кластеров. Изучение тенденций автор построил на следующей структуре индикаторов научно-технического развития кластеров:

1. «SIC»" - консолидация интеллектуального капитала: доля заявок на объекты интеллектуальной собственности (от общего объема кластера), инициированных якорным предприятием,\%.

2. «РСТ» - мультидисциплинарность исследований: доля заявок на объекты интеллектуальной собственности (от общего объема кластера), относящихся к отраслевой (продуктовой) специализации всеми предприятиями,\%.

3. «SE» - наукоемкость образовательных центров: доля предложенных образовательными организациями (без учета входящих в них НИИ) заявок на объекты интеллектуальной собственности (от общего объема кластера),\%.

4. «РІС» - межкластерная кооперация: доля заявок на объекты интеллектуальной собственности (от общего объема кластера), поданных в партнерстве с субъектами сторонних кла-

* Переменные отображены в последующих таблицах публикации. 


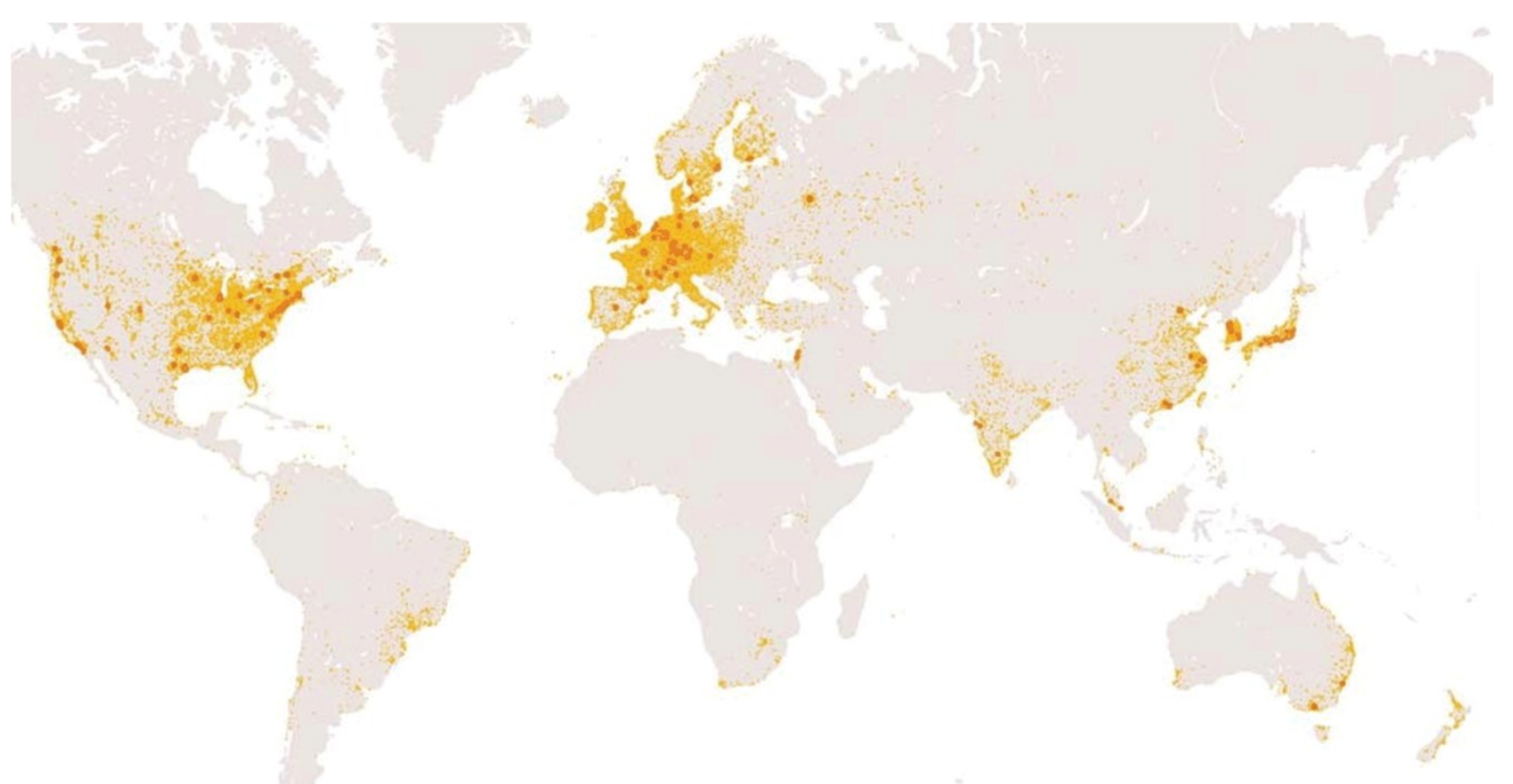

Puc. 1. Пространственная концентрация глобального кластерного развития, интерпретировано автором по картографической информации «Глобального инновационного индекса» (GII, INSEAD, 2018, [11]).

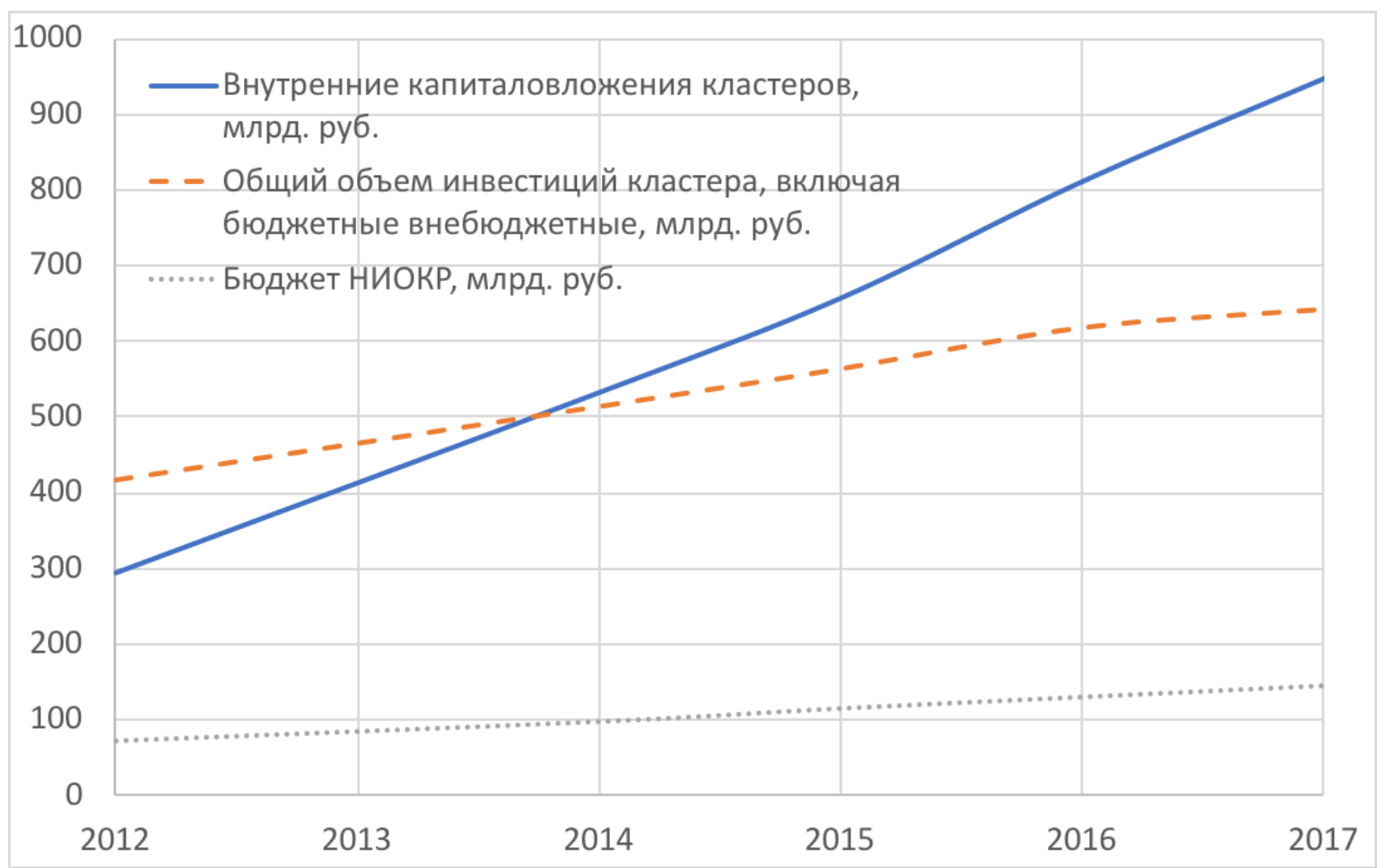

Puc. 2. Динамика совокупных (104-х) валовых экономических показателей российских кластеров (интерпретировано автором по данным «Кластерная политика», «Corvus», [2]). 
стеров,\%.

Фрагмент статистического наблюдения отражен в табл. 1 - показатели научно-исследовательской деятельности 10-ти лучших кластеров по рейтингу GII. В тоже время отраслевые и секторальные (по уровням технологичности - в классификации OECD) исследования 100 глобальных кластеров, выполненные автором, представлены в виде индикаторов в табл. 2. Приведены, рассчитанные автором, средняя по всем индикаторам и стандартное отклонение показателя в выборке исследования. Для понимания отдельных тенденций и факторов автором изучены кейсы 20-ти лучших, с позиции научно-технического развития, кластеров.

Статистический анализ интерпретированных автором данных и кейсов позволил сформулировать 5 тенденций глобального кластерного развития, выражающих направленность структурных, институциональных изменений.

Тенденция 1: высокая степень специализации субъектов кластеров. Объективны признаки институционализации по видам деятельности субъектов кластеров. Причем специализация строится относится этапов инновационного цикла: НИОКР (обнаруживается и специализация в цикле исследований и разработок, например, «прототипирование», «технические писатели» и др.); производство; маркетинг; сервис; утилизация. Данная тенденция основывается на незначительном уровне консолидации НИОКР в якорном (производственном) предприятии - показатель SIC (табл. 1) невысок 6-14\%. Причем высокий уровень концентрации в отдельных случаях (вывод по изучению кейсов «Эйндховен», «Сан-Диего», «Штутгарт» и др.) не опровергает тезис: в данных кластерах якорное предприятие было заказчиком и инвестором НИОКР, соответственно и правообладателем интеллектуальной собственности, а исполнителями исследовательских работ специализированные предприятия (включенные в кластер). Данная тенденция вполне отвечает «рыночной» парадигме кластера как формы хозяйственного объединения, противопоставляемой корпоративным процессам интеграции через слияния и поглощения. Выделяющиеся специализированные субъекты масштабируют свою деятельность через производство и услуги предприятиям вне кластера.

Тенденция 2: экономический прорыв в кластерах, инновационные технологии которых от- носятся к VI технологическому укладу (табл. 1). Концепция инновационных перспектив «NBIC», сформулированная Roco M.C., Sims W. (2002, [9]), определяет технологические направления инновационного прорыва, наиболее перспективные отраслевые зоны инвестирования. В качестве таковых определяются следующие (входящие в англ. аббревиатуру): нано-, био-, инфо- и когнитивные технологии. 71\% кластеров из анализируемой выборки относятся к обозначенным технологиям. Кластеры, реализующие технологии NBIC, образуют ядро высокотехнологичного сектора. В котором обнаруживается наиболее высокое значение индикатора наукоемкости образовательных центров SE (11,22\%, табл. 2), обнаруживающее значительную роль человеческого капитала в исследованиях NBIC.

Тенденция 3: меж- и мульти- дисциплинарность программ научно-исследовательских и опытно-конструкторских работ в кластерах. Например, в фармацевтических кластерах в перспективные программы НИОКР включены направления: биология, биофизика, биохимия, радиационные исследования и т.п. сферы, имеющие пограничный для фармакологии характер.

Обратим внимание на среднее значение индикатора концентрации ОИС в рамках единичной предметной, отраслевой сферы (РСТ) невысоко - 15,19\% (вариация - 8,25). Данное явление объясняется в концепции «конвергенции знаний» (NBIC - Roco M.C., и др., 2002, [9]), подразумевающей ожидание прорывов в научно-технической сфере в комбинаторике передовых технологий NBIC (нано-, био-, инфо- и когнитивные) - «биоинформатика», «нанобиология» и др. Именно поэтому формирование программ перспективных долгосрочных (среднесрочные - тенденция 2, отражены как технологии NBIC) исследований и разработок кластеров учитывает смежные и комбинаторные области исследований.

Тенденция 4: рост кооперации в научных исследованиях между кластерами. Природа данной тенденции также объясняется концепцией «конвергенции знаний». Если ресурсный потенциал НИОКР кластера в пограничной сфере недостаточен, логично возникает долгосрочная (оформленная в программах перспективных НИР) кооперация со сторонними профильными объединениями. «Межкластерная кооперация» Becqueriaux S. И др. (2013, [4]) относительно новая тенденция, но объективно наблюдаемая 


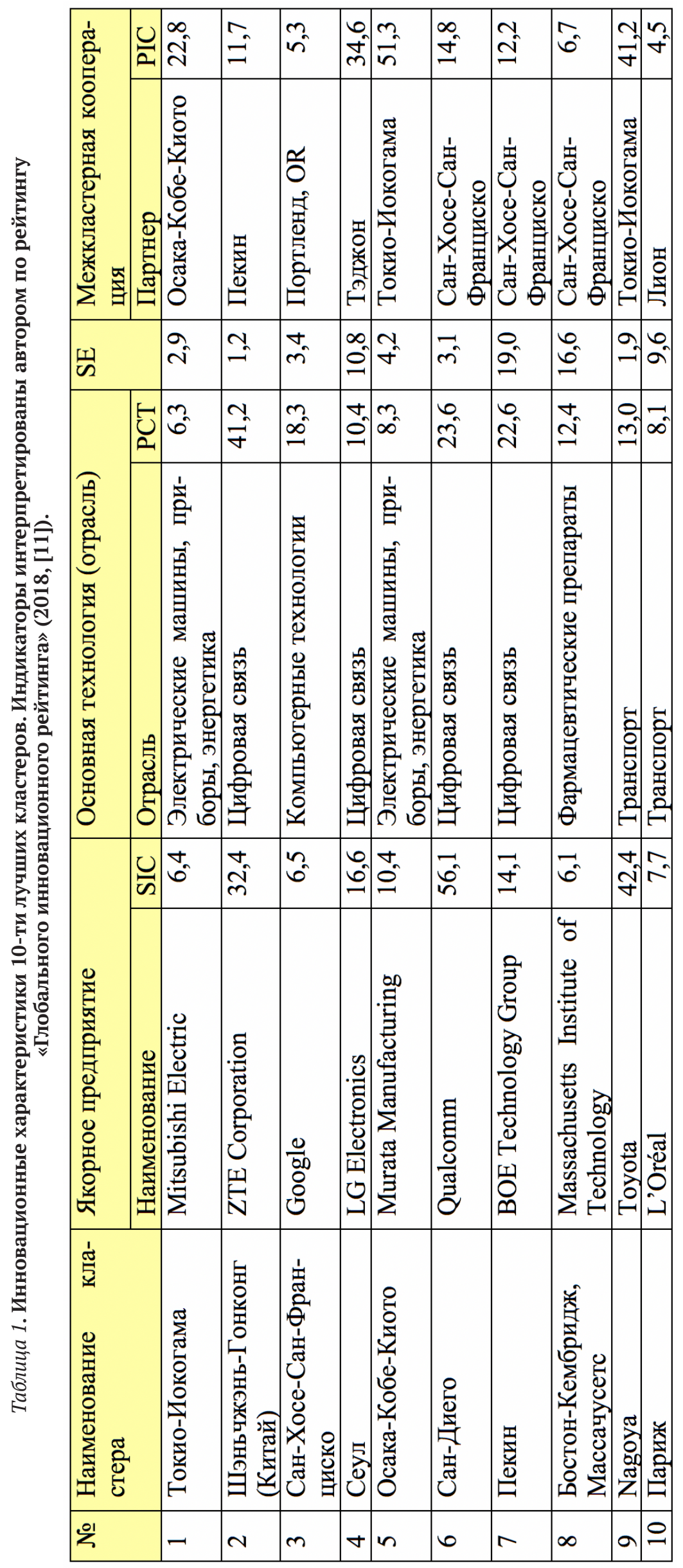


Таблица 2. Секторальный и отраслевой анализ индикаторов научно-технического развития кластеров. Исходные данные интерпретированы в контексте исследования автором.

\begin{tabular}{|c|c|c|c|c|}
\hline Сектора, отрасли & Кластеров, ед. & PCT & SE & PIC \\
\hline \multicolumn{5}{|l|}{ По уровню технологичности } \\
\hline Высокотехнологичные & 7 & 13,69 & 11,22 & 14,33 \\
\hline Среднетехнологичные & 8 & 17,67 & 6,58 & 14,12 \\
\hline Низкотехнологичные & 1 & 7,90 & 8,05 & 6,70 \\
\hline \multicolumn{5}{|l|}{ По отраслям } \\
\hline Химия материалов & 4 & 8,13 & 5,58 & 12,15 \\
\hline Биотехнология & 2 & 10,75 & 12,75 & 6,90 \\
\hline Гражданское строительство & 2 & 20,20 & 4,90 & 6,15 \\
\hline Компьютерные технологии & 11 & 15,78 & 14,05 & 13,53 \\
\hline Цифровая связь & 16 & 16,33 & 8,99 & 12,01 \\
\hline Электрические машины & 7 & 13,93 & 9,01 & 40,39 \\
\hline Двигатели, насосы, турбины & 2 & 25,45 & 1,85 & 8,75 \\
\hline Пищевая химия & 1 & 7,50 & 12,40 & 2,90 \\
\hline Мебель & 1 & 7,90 & 6,00 & 9,50 \\
\hline Механические элементы & 1 & 44,00 & 0,50 & 28,00 \\
\hline Медицинские технологии & 17 & 16,08 & 12,86 & 16,32 \\
\hline Оптика & 2 & 13,55 & 0,25 & 25,55 \\
\hline Органическая химия & 6 & 12,25 & 8,30 & 10,75 \\
\hline Фармацевтические препараты & 15 & 9,31 & 18,02 & 7,46 \\
\hline Полупроводники & 4 & 14,06 & 11,61 & 18,52 \\
\hline Текстильные машины & 1 & 9,90 & 10,10 & 3,90 \\
\hline \multirow[t]{2}{*}{ Транспорт } & 7 & 13,17 & 6,74 & 17,73 \\
\hline & Средняя & 15,19 & 8,47 & 14,15 \\
\hline \multicolumn{2}{|c|}{ Стандартное отклонение } & 8,25 & 4,68 & 9,16 \\
\hline
\end{tabular}

на уровне индикаторов (табл. 1,2). Передовые кластеры имеют значительную долю объектов интеллектуальной собственности, сформированных в партнерстве с другими объединениями. Средняя величина индикатора PIC (табл. 2) значительна - 14,15\% (при вариации переменой - 9,16). В отраслевом разрезе наблюдаются и рекорды межкластерной кооперации: электрические машины - 40,39\%; механика $28 \%$; оптика - 25,55\%). И это вполне объяснимо, данные отрасли (производящие «средства труда»), во-первых, эффективно используют комбинаторные технологические разработки, а, во-вторых, их продукция ориентирована на потребителей, находящихся в других кластерах. Таким образом, данная тенденция может рассматриваться как новая волна концентрации исследований и разработок, построенная на междисциплинарных, межкластерных программах научно-технического развития.

Тенденция 5: сохранение позиции лидера кластера у производственных предприятий. Обнаруженные тенденции 2-4 интерпретировались в теории экономики промышленности как смещение лидерства в кластере от производства к науке, консолидируемой образовательным организациям. Ряд экономистов (Reid A. и др., 2008, [8]; Storper M., 2010, [10]; Lung L. и др., 2014, [6]; Алексеев А.А., Хлебников К.В., 2016, [1]; и др.) прогнозировали, что в высокотехнологичных кластерах якорными предприятиями станут ВУЗы, консолидирующие воспроизводство человеческого капитала, фундаментальные исследования и прикладные НИР. Во многом, предпосылкой такой позиции является и концепция «тройной спирали» (Etzkowitz H., 2011, [5]). Действительно индикатор доли ОИС, генерируемых образовательными организациями в высокотехнологичном секторе, наибольший 11,22\% (табл. 2). Но средняя величина индикатора сохраняется низкой - 8,47\% (незначительна и вариация - 4,68). Поэтому автор формализу- 
ет тенденцию сохранения производственных предприятий как лидеров кластера. Промышленные предприятия, как правило, выступают в роли заказчика и инвестора, выгодоприобретателя результатов научно-исследовательской деятельности. Кейс-анализ (табл. 1) объективно раскрывает данную тенденцию. Итак, сформулированные автором 5 тен- Федерации. денций можно рассматривать как перспективу структурной, институциональной трансформации глобального кластерного развития. Данная перспектива должна быть учтена в формирующемся национальном мониторинговом (нормативные акты) и нормативном полях, регулирующих кластерную политику Российской

\section{Библиографический список}

1. Алексеев А.А., Хлебников К.В. Анализ специфики организации высокотехнологичных инновационных кластеров // Экономические науки. 2016. № 142. С. 64-68.

2. Кластерная политика: концентрация потенциала для достижения глобальной конкурентоспособности / Под ред. И.М. Бортника, Л. М. Гохберга, А.Н. Клепача, П.Б. Рудника, О. В. Фомичева, А.Е. Шадрина. Санкт-Петербург. 2015. 356 с.

3. Тоффлер Э. Третья волна. Москва. 1999.

4. Becqueriaux S., Milon F. New inter-clusters collaboration methodologies. Presentazione di Sandrine Becqueriaux and Franck Milon, Lille Métropole, al Festival dell 'Innovazione 2013 nell’ambito di «Crossover creativity lab»— The HUB, c/o Fiera del Levante - 24 maggio 2013.

5. Etzkowitz, H. The Triple Helix Concept. Stanford University Triple Helix Research Group. 11 July 2011.

6. Lung L., Maw-Shin Hsu, Feng-Jyh Lin, Yi-Min Chen, Yi-Hsin Lin. The effects of industry cluster knowledge management on innovation performance. Journal of Business Research, № 67, 2014, 734-739.

7. OECD: Science, Technology and Industry Outlook. - OECD, 2018.

8. Reid A., Miedzinski M. Sectoral Innovation Watch in Europe: Eco-Innovation. Brussels: Europe Innova: Innovation watch, 2008.

9. Roco M. C., Sims W. Bainbridge Converging Technologies for Improving Human Performance: nanotechnology, biotechnology, information technology and cognitive science // NSF/DOC-sponsored report National Science Foundation, Arlington, Virginia, 2002.

10. Storper M. Regional technology policies in Europe: A reflection on TSER research projects, 1998-2000, and where to go from there. Paper prepared for the Workshop on the Regional Level of Implementation of Innovation and Education \& Training Policiesí. European Commission, Research Directorate-General XII. Brussels, November 23-14, 2000.

11. The Global Innovation Index 2017: Innovation Feeding the World, INSEAD, 2018. 